\title{
Fatty acids of human milk - a review
}

\author{
Rafał Bobiński ${ }^{1}$ a and Jagna Bobińska²
}

\author{
Department of Biochemistry and Molecular Biology, Faculty of Health Sciences, University of Bielsko-Biala, Bielsko-Biala, Poland \\ 2 Copernicus High School, Bielsko-Biala, Poland
}

\begin{abstract}
The composition of human milk is the result of the evolution of mammals over millions of years. Among the most important components of milk are fatty acids. Approximately $85 \%$ are saturated and monounsaturated fatty acids - the rest are polyunsaturated one. Their role is to provide energy and immunity and to serve as buildings blocks, as well as assisting the hormonal system and the metabolism of fats, carbohydrates and proteins. The structural differences between fatty acids determine their biodiversity and give them particular physiological importance. Correct development of the nervous system, retina and other structures depend on an adequate supply of both these fatty acids during intrauterine development and in the newborn and infant stages. The fats present in milk form milk fat globules structures that do not appear in milk formula prepared using vegetable oils. Apart from the mother's diet, other sources of fatty acids are endogenous biosynthesis in the mammary gland and the fat deposits from which the fatty acids are released. Evolution of the mother's body has also created adaptive mechanisms that adjust the amount of fatty acids in milk to the state of health and needs of the child. These mechanisms go some way to creating a buffer with regard to dietary shortages experienced by pregnant/breastfeeding women, and optimalise the composition of milk fatty acids depending on the age of the pregnant woman, the birth weight of the infant and the efficiency of the placenta during pregnancy.
\end{abstract}

Keywords: Fatty acids, human milk, preterm, mother's diet

\section{Abbreviation}

Appropriate for gestational age (AGA), arachidonic acid (C20:4 n-6; AA), capric acid (C10:0 CA), docosahexaenoic acid (C22:6 n-3; DHA), eicosapentaenoic acid (C20:5 n-3; EPA), fatty acid (FA), lauric acid (C12:0 LAA), long chain polyunsaturated fatty acids (LCPUFA), linoleic acid (C18:2 n-6; LA), mature milk (MM), medium chain fatty acids (MCFA), milk fat globule membrane (MFGM), monounsaturated fatty acids (MUFA), myristic acid (C14:0 MA), pre-term birth (PTB), small for gestational age (SGA), transitional milk (TM), $\alpha$-linolenic acid (C18:3 n-3; ALA), $\gamma$-Linolenic acid (C18:3 n-6; GLA).

\section{Introduction}

A woman's milk is the only natural source of nutrition for a child in the first few months of life. The unique composition of the milk and its extraordinary complex structure, composed of macromolecules and particles, is the result of 150 million years of mammal evolution [1]. Over time, this has produced a wholesome food providing nourishment and immunological protection, whose composition is most probably adapted to the state of health and needs of the child. One of the most important substances in milk is fatty acids (FAs), which ensure the correct development of the child in the prenatal, postnatal and infant stages. [2-4]. These FAs are responsible for the energy processes taking place in cells and are the principal building material of cell membranes, as well as being precursors of important metabolic compounds such as prostacyclins, prostaglandins, thromboxanes and leukotrienes. FAs differ from one another by the length of their carbon chain and the number of unsaturated bonds. The structural differences between FAs determine their biodiversity and make them of outstanding physiological significance. Long chain polyunsaturated fatty acids (LCPUFA) are of particular importance [59]. A correct supply of these in the intrauterine, postnatal and infant stages of development ensures the proper development of the nervous system, the retina and other structures [10-13]. Amongst the most important LCPUFAs are the so-called essential fatty acids (EFAs) - linoleic acid (C18:2 n-6; LA) precursor of the n- 6 family and $\alpha$-linolenic acid (C18:3 n-3; ALA) precursor of the $n-3$ family. These form biologically important long chain polyunsaturated derivatives such as: $\gamma$-Linolenic acid (C18:3 n-6; GLA), Arachidonic acid (C20:4 n-6; AA), Eicosapentaenoic acid (C20:5 n-3; EPA) and Docosahexaenoic acid (C22:6 n-3; DHA). 


\section{Lipid fractions of human milk}

The average fat content in a woman's milk is around $3.8-3.9 \mathrm{~g} / 100 \mathrm{ml}$ but this figure depends on many factors, the most important of which appear to be the lactation period, as well as the diet and dietary habits of mothers, which are often dependent on geographical location [14-16]. Human milk fat provides nearly $50 \%$ of the energy intake of young infants, corresponding to an intake of around 25 $\mathrm{g}$ /day up to 6 months of age [17-19]. The main fat component is triacylglycerols (TAGs), which make up more than 98\% of milk fat. The remaining part consists of phospholipids - around 0.7\%, and cholesterol - around 0.5\%. Lipolysis products, in other words free FAs, and mono and diacylglycerols are found in milk in trace amounts [20]. TAGs are built of glycerol molecules bonded to three FAs. This structure facilitates the transport of strongly hydrophobic FAs in a hydrophilic environment. The stereospecific structure of glycerol promotes highly specific interactions both with esterifying enzymes and with lipolytic enzymes, which recognise glycerol hydroxyl groups. As a result of these interactions, the appropriate FAs are built into the glycerol molecule within the mammary gland and then released in the child's digestive system in the correct order, thus satisfying the child's needs. More than $95 \%$ of the total milk lipids are in the form of a globule of between 0.1 and 15 $\mu \mathrm{m}$ in diameter. These liquid fat droplets are surrounded by

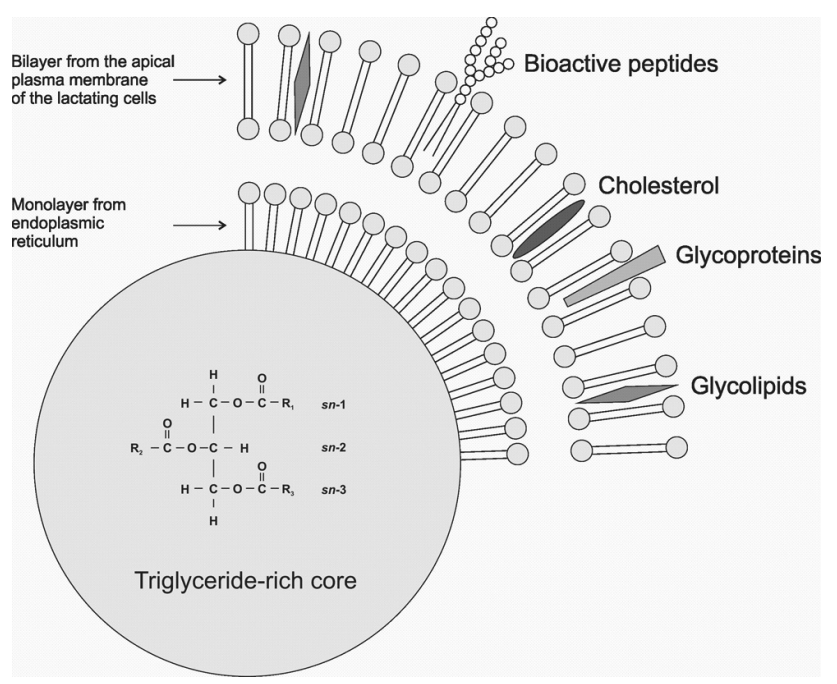

Figure 1. Structure of the milk fat globule membrane. Triacylglycerols form lipid droplets in the endoplasmic reticulum of the mammary gland, where they are surrounded by a single layer of polar lipids. These intracellularly formed structures move to the apical surface of the mammary epithelial cells where they pass through the membrane into the alveolar lumen and milk plasma. As a result of passing through the cell membrane, the droplets are additionally surrounded by a double lipid layer created in the apical plasma membrane. a thin trilayer membrane 8-10 nm thick (Figure 1). During the biosynthesis of milk, TAGs form lipid droplets in the endoplasmic reticulum of the mammary gland, where they are surrounded by a single layer of polar lipids $[1,21]$. These intracellularly formed structures move to the apical surface of the mammary epithelial cells where they pass through the membrane into the alveolar lumen and milk plasma. As a result of passing through the cell membrane, the droplets are additionally surrounded by a double lipid layer created in the apical plasma membrane. Eventually, a human milk fat globule is formed, surrounded by a milk fat globule membrane (MFGM), consisting principally of phosphatidylocholines, phosphatidylethanolamines and sphingomyelins, as well as LCPUFAs [22-24]. MFGM is a key structure which ensures the unique composition of human milk and which is not provided by food substitutes prepared on the basis of vegetable oils [25]. Several randomised trials have studied formula enriched with MFGM obtained from cow's milk. In children fed with formula enriched with MFGM, less otitis media was observed, and there was a decreased duration of diarrhoea episodes [26] and a better development of cognitive abilities compared to a group fed only with standard formula $[27,28]$. It must also be emphasised that the results of the group fed on the MFGM enriched formula are similar to the results of the breastfed group.

The amount of FAs in the milk is not constant. This depends mainly on the lactation period and therefore the type of milk produced (colostrum, transitional milk (TM), mature milk (MM), feeding stages (foremilk, hindmilk), as well as the mother's diet and the health of the newborn child. Irrespective of the type of milk, the dominating FAs are saturated and monounsaturated fatty acids (MUFAs) $[20,29,30]$ (Figure 2). Their percentage share in the pool of FAs in milk is between $83 \%$ and $86 \%$, of which approximately half are saturated acids and the other half MUFAs. Among the MUFAs, oleic acid $(\mathrm{C} 18: 1, \mathrm{OA})$ is the most prevalent, constituting around $90 \%$ of the MUFAs in human milk. OA also has the highest percentage share in the total pool of FAs in milk. In contrast to saturated acids and MUFAs, LCPUFAs constitute only $14-17 \%$ of the pool of FAs in human milk. Among LCPUFAs, the precursor of the n-6 family, linoleic acid (C18:2 n-6; LA) dominates, with around $10 \%$ of the pool of FAs in milk. The total amount of its mostly twenty or more carbon derivatives, including AA, does not exceed $1.5 \%$. In the $n-3$ family, the precursor from this group, $\alpha$-linolenic acid (C18:3 n-3;ALA) also dominates. However, the amount is 10 times less than LA, at around $0.7-0.9 \%$. Meanwhile, the total amounts of twenty or more carbon derivatives (including EPA and DHA) is around the $0.5 \%$ mark. Analysis of changes in the amounts of FAs between colostrum and mature milk in terms of the healthy appropriate for gestational age babies (AGA), shows 


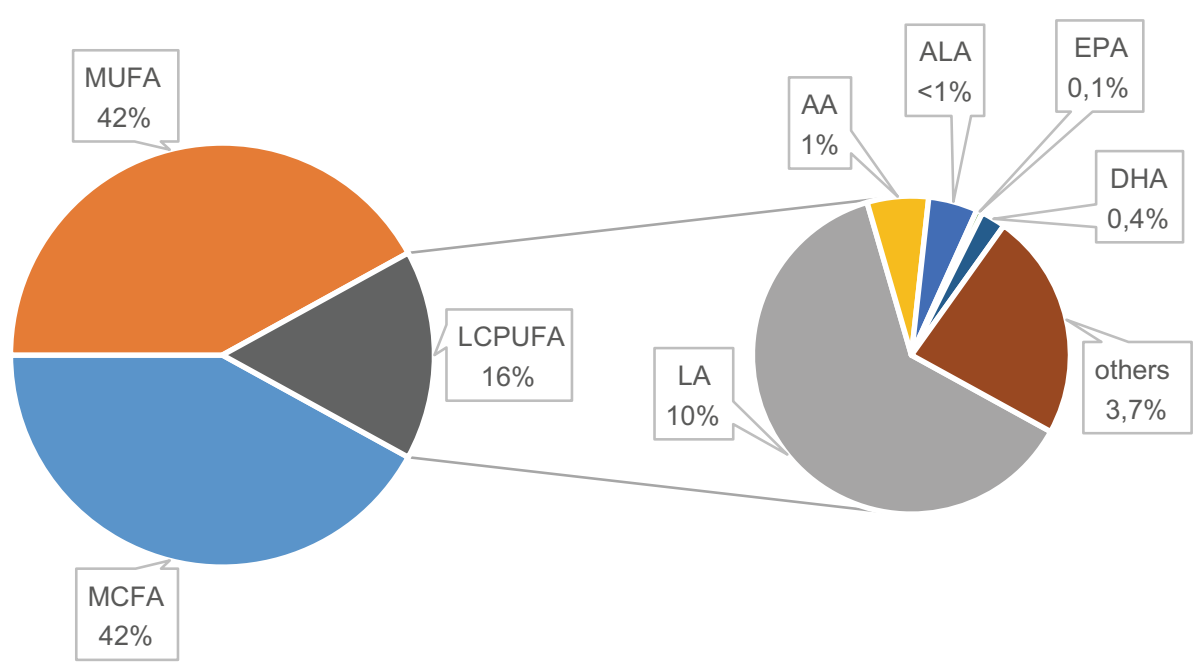

Figure 2. Fatty acids in mother's milk. The results are expressed as a percentage (\% wt/wt) of all FAs detected. MUFA (Monounsaturated fatty acids), MCFA (Medium chain fatty acids), LCPUFA (Long chain polyunsaturated fatty acids), Linoleic acid (C18:2 n-6; LA), $\alpha$-linolenic acid (C18:3 n-3; ALA), Arachidonic acid (C20:4 n-6; AA), Eicosapentaenoic acid (C20:5 n-3; EPA) and Docosahexaenoic acid (C22:6 n-3; DHA).

differences in two groups of FAs (Table 1). The first are saturated acids with a carbon chain length of C10-C12. Their presence in the pool of FAs in mature milk increases significantly in relation to colostrum by $100-110 \%$ for C10, and by almost $50 \%$ for C12. The second group are LCPUFAs and their precursors (LA and ALA). The amount of LA and ALA increases in mature milk, while the amount of metabolites decreases, compared to that observed in transitional milk to approximately $60-65 \%$ for AA, and $50 \%$ for DHA. These percentages are average values obtained on the basis of analysis of tests on human milk from various locations around the world. Detailed analysis of the FA profile for selected populations, however, reveals differences in the amounts of individual FAs. The greatest discrepancies in the composition of FAs are seen between highly developed countries such as the USA and western European countries, and African countries [20,29,31-34]. The amount of fat in milk also changes depending on the stage of feeding and the time of day. In foremilk, the fat content is at the level of $2 \%$, while in hindmilk the amount rises to $6 \%[35,36]$. Throughout the day, the amount of fat rises and then falls at night. The reasons for the increase in fat content during breast feeding stages have not been explained. One possibility suggested is that fat globules attach to the alveolar surface and, during breastfeeding, the morphology of the lactocyte and the shape of the alveolus change resulting in a decrease in the available surface. This, together with the greater shear forces generated towards the end of the feeding session, leads to the secretion of more fat globules with milk towards the end of the feed $[28,37]$.

\section{Influence of the mother's diet on the composition of FAs in milk}

During intrauterine development, and in the first months of life, a child's nutritional requirements undergo significant changes depending on the age of the foetus/child and its health. The wealth of nutrients in a woman's diet, in combination with the biodiversity of FAs contained in milk, make understanding the biochemical mechanisms responsible for the synthesis of milk FA extremely difficult. As a result of evolution [6], a woman's body has created adaptive mechanisms that adjust the composition of milk FAs to suit the state of health and nutritional needs of the child. These mechanisms go some way to creating a buffer with regard to dietary shortages experienced by pregnant/breastfeeding women $[6,15]$, and optimise the composition of milk FAs depending on the age of the pregnant woman, birth weight, the efficiency of the placenta during pregnancy etc. [16]. In particular, however, the composition of human milk FAs depends on three factors: endogenous biosynthesis in the mammary gland $[16,38]$, the release of FAs from tissue deposits laid down during pregnancy [17, 39], and most importantly - the current diet of the breastfeeding mother $[20,40]$. According to "Dietary guidelines for Americans" (2005 U.S. Department of Health) and European Food Safety Authority fats should constitute about $20 \%-35 \%$ of calories consumed [41, 42]. In line with current recommendations and expert opinions, FAs should be a key component of the diet of feeding mothers. The diet should 
Table 1. Fatty acids in transitional milk and mature milk. The results are expressed as a percentage (\% wt/wt) of all FAs detected. FA - fatty acid, AGA - appropriate for gestational age, PTB - pre-term birth, SGA - small for gestational age. TM - transitional milk, MM - mature milk. More important fatty acids are in bold: capric acid (C10:0 CA), lauric acid (C12:0 LAA), myristic acid (C14:0 MA), linoleic acid (C18:2 n-6; LA), $\alpha$-linolenic acid (C18:3 n-3; ALA), $\gamma$-Linolenic acid (C18:3 n-6; GLA), Arachidonic acid (C20:4 n-6; AA), Eicosapentaenoic acid (C20:5 n-3; EPA) and Docosahexaenoic acid (C22:6 n-3; DHA). The most important fatty acids discussed in the publication are marked in bold.

\begin{tabular}{|c|c|c|c|c|c|c|}
\hline \multirow[b]{2}{*}{ FA (\%wt/wt) } & \multicolumn{2}{|c|}{ AGA } & \multicolumn{2}{|c|}{ PTB } & \multicolumn{2}{|c|}{ SGA } \\
\hline & $\mathrm{TM}$ & MM & TM & MM & TM & MM \\
\hline C10:0 (CA) & 0.353 & 0.725 & 0.399 & 0.958 & 0.461 & 0.894 \\
\hline C11:0 & 0.000 & 0.012 & 0.000 & 0.011 & 0.000 & 0.005 \\
\hline C12:0 (LAA) & 2.307 & 3.395 & 2.811 & 4.849 & 2.698 & 4.485 \\
\hline C13:0 & 1.291 & 0.839 & 0.959 & 0.040 & 0.331 & 0.031 \\
\hline C14:0 (MA) & 6.139 & 6.468 & 7.092 & 7.196 & 7.753 & 8.224 \\
\hline C14:1 & 0.258 & 0.373 & 0.254 & 0.382 & 0.234 & 0.283 \\
\hline C15:0 & 0.295 & 0.360 & 0.273 & 0.339 & 0.284 & 0.263 \\
\hline C15:1 & 0.084 & 0.069 & 0.095 & 0.086 & 0.069 & 0.079 \\
\hline C16:0 & 23.611 & 23.363 & 23.328 & 22.721 & 22.401 & 21.264 \\
\hline C16:1t & 0.609 & 0.497 & 0.578 & 0.448 & 0.517 & 0.436 \\
\hline C16:1C & 2.966 & 3.148 & 2.753 & 3.090 & 3.084 & 2.969 \\
\hline C17:0 & 0.268 & 0.319 & 0.283 & 0.265 & 0.239 & 0.192 \\
\hline C17:1 & 0.180 & 0.259 & 0.163 & 0.168 & 0.135 & 0.167 \\
\hline C18:0 & 5.843 & 6.289 & 5.761 & 5.689 & 5.576 & 6.316 \\
\hline C18:1t & 0.763 & 0.000 & 0.406 & 0.000 & 0.773 & 0.000 \\
\hline C18:1C & 39.928 & 38.877 & 39.759 & 38.784 & 40.502 & 40.108 \\
\hline C18:2n6 (LA) & 9.260 & 10.085 & 9.250 & 10.443 & 9.751 & 9.651 \\
\hline C18:3n6 (GLA) & 0.058 & 0.111 & 0.076 & 0.103 & 0.092 & 0.074 \\
\hline C18:3n3 (ALA) & 0.747 & 0.889 & 0.779 & 0.895 & 0.697 & 0.953 \\
\hline C20:0 & 0.225 & 0.300 & 0.242 & 0.204 & 0.217 & 0.239 \\
\hline C20:1 & 0.802 & 0.567 & 0.793 & 0.346 & 0.717 & 0.319 \\
\hline C20:2 & 0.383 & 0.237 & 0.344 & 0.265 & 0.333 & 0.182 \\
\hline$C 20: 3 n 6$ & 0.460 & 0.355 & 0.504 & 0.376 & 0.441 & 0.285 \\
\hline C20:4n6 (AA) & 0.745 & 0.543 & 0.745 & 0.549 & 0.673 & 0.486 \\
\hline$C 20: 3 n 3$ & 0.088 & 0.055 & 0.090 & 0.054 & 0.069 & 0.037 \\
\hline C22:0 & 0.113 & 0.092 & 0.126 & 0.093 & 0.105 & 0.068 \\
\hline C22:1 & 0.189 & 0.160 & 0.194 & 0.096 & 0.154 & 0.117 \\
\hline C20:5n3 (EPA) & 0.086 & 0.105 & 0.103 & 0.078 & 0.080 & 0.064 \\
\hline $\mathrm{C} 24: 0$ & 0.248 & 0.101 & 0.235 & 0.118 & 0.216 & 0.094 \\
\hline $\mathrm{C} 24: 1$ & 0.212 & 0.069 & 0.220 & 0.043 & 0.175 & 0.020 \\
\hline$C 22: 5 n 3$ & 0.223 & 0.156 & 0.217 & 0.141 & 0.197 & 0.148 \\
\hline C22:6n3 (DHA) & 0.429 & 0.361 & 0.450 & 0.337 & 0.391 & 0.392 \\
\hline C23:0 & 0.067 & 0.030 & 0.066 & 0.047 & 0.075 & 0.016 \\
\hline$C 22: 2$ & 0.171 & 0.063 & 0.167 & 0.059 & 0.163 & 0.063 \\
\hline
\end{tabular}

contain an appropriate amount of FAs and substances necessary for their biosynthesis such as carbohydrates for example, but also components that regulate the activity of enzymes participating in FA metabolism. Furthermore, the composition of the milk is also affected by non-metabolic factors such as the socio-economic status of women [31, 43], their lifestyle, and their dietary habits [44-46]. These factors differ greatly between populations, principally between oriental and occidental $[47,48]$.

To satisfy a child's growth and metabolic needs, a sufficient supply of EFAs such as LA and ALA, n-3 and n-6
FAs, such as DHA, and AA, as well as MUFAs and medium chain fatty acids (MCFAs) are necessary. There is a particular need for LA, ALA and their derivatives AA and DHA in the first six months of life. This is the period of the most dynamic development of a child's nervous system, and the above-mentioned FAs play the role of main building blocks. The intensity of metabolic processes at this stage is so high that satisfying the needs of the child are a real challenge for the mother's body. The brain at this time reaches a mass that is half that of an adult's brain [49-51]. Newly formed nerve cells needs large amounts of LCPUFAs, 
especially DHA, in order to maintain the process of synaptogenesis. The synapses proliferate logarithmically at a rate of 40,000 per second $[51,52]$ and are particularly rich in DHA, which constitutes $35 \%$ of the pool of acids present in phospholipids containing serine and ethanoloamine $[53,54]$. Phospholipids containing DHA and serine are of particular importance. They are found mainly in the internal cell membrane monolayer, where, apart from functioning as building blocks, they play the role of membrane enzyme cofactor, affecting, amongst others, the activation of protein kinase $\mathrm{C}$, which participates in the transmission of signals. They also contribute to an increase in the activity of the sodium-potassium pump [55-57]. Stimulation of the above-mentioned mechanisms contributes to the development of cognitive parameters [58], an increased resistance to stress, and a lower susceptibility to depression [59], as well as many other beneficial effects. In contrast to adults, the majority of infants cannot synthesise enough LCPUFAs from EFA [60]. The mother's milk remains the principal source of these FAs for the child. Research has shown that a mother's consumption of EFAs correlates positively with the amount of these acids in her milk [17, 61]. However, only part of the EFA consumed passes directly into the milk. The remaining part is deposited in tissues (mainly fat tissues), and is used for LCPUFA synthesis and also converted into $\mathrm{CO}_{2}[62,63]$. Studies using EFA marked with the carbon isotope $\mathrm{C}^{13}$ demonstrated that around $30 \%$ of the LA present in the milk is directly transferred from the diet [39, 63]. The rest comes from body stores accumulated by the mother, mainly in fat tissue (Figure 3). The proportion of ALA in the mother's milk derived directly from the diet is $65 \%$ [64]. Both LA and ALA originating in the diet undergo conversion to the derivatives $n-3$ and $n-6$, but the ALA coming from the body stores and contributing to the milk ALA seems to be much lower than the contribution of stored LA to milk LA. Supplementing ALA while breastfeeding does not increase the amount of DHA in the mother's milk $[65,66]$. It was observed, however, that supplementing the mother's diet with ALA from the sixth month of pregnancy until the sixth month of lactation resulted in a three- to fourfold increase in DHA in her milk, but only in the first three months of lactation. No further effect of ALA supplements on DHA levels were found in months four to six of lactation [67]. The lack of correlation between ALA in the diet and DHA in the milk is primarily the result of the human body's low efficiency in converting ALA into long chain FAs such as EPA or DHA [68]. Only $2 \%-10 \%$ of ALA is transformed into EPA and DHA [69]. Other authors suggest that around 7\% of ALAs are converted into EPA and only $0.013 \%$ into DHA. Studies have shown that excessive supplements or intake of EFAs by the mother are not beneficial for the child's organism as this (in particular LA) can lower the percentage of AA in the milk, and, in the case of DHA, even reduce the level to

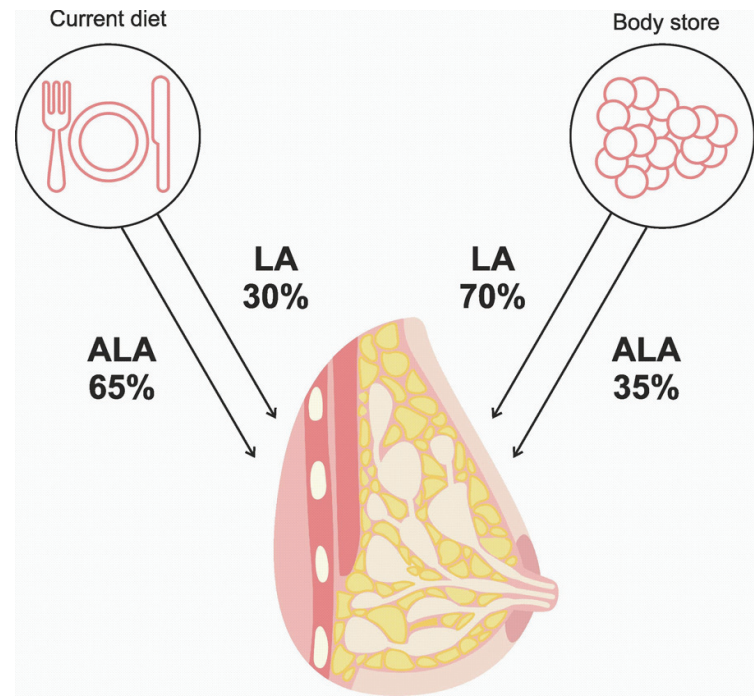

Figure 3. The source of essential fatty acids in mother's milk. ALA - $\alpha$ linolenic acid, LA - linoleic acid.

just trace amounts. Metabolic suppression is linked to the common metabolic pathway of n-3 FAs and n- 6 FAs in the processes of desaturation and carbon chain extension. The reactions are catalysed by two desaturases: $\Delta-5$ and $\Delta-6$. If the diet of a pregnant woman is abundant in fish and seafood, the increased amount of EPAs may - through inhibition of $\Delta-5$ desaturase - slow the creation of AA and its derivatives [70-72]. If the maternal diet is rich in plant oils, such as sunflower-seed oil, safflower oil or corn oil, which contain large amounts of LA, then fewer DHA are produced from ALA as a result of $\Delta-6$ desaturase inhibition leading to decreased EPA biosynthesis. The imbalance between dietary n-3 and n-6 FAs may lead to structural changes in cell membranes in which the composition of LCPUFA lipid fraction is dependent on the current LCPUFA concentration in maternal blood. To satisfy the needs of the child, the mother's correct intake of DHA is more important. Clinical studies conducted in Greece, the USA, Korea and China have confirmed the positive or strongly positive correlation between amounts of DHA in a breastfeeding mother's diet and the amount of DHA in her milk $[17,68,73-80]$. The recommended adult dose for both EPA and DHA together is $500 \mathrm{mg} /$ day [81]. Studies have shown that intake of these FAs, especially DHA, varies. This is partly due to the geographical region and the availability of a suitable diet rich in such foods as fish and seafood. Women living in an inland area, for example, have an intake of $30 \mathrm{mg}$ /day, while in a coastal area it was $180 \mathrm{mg} /$ day [46] (Bangladesh 30 $\mathrm{mg} /$ day [82], Sudan $33 \mathrm{mg} /$ day [83], New Mexico 47 $\mathrm{mg} /$ day [84], Sweden $120 \mathrm{mg} /$ day [17], Poland $160 \mathrm{mg} /$ day [85], Canada $186 \mathrm{mg} /$ day [86]). The ratio of n-3 family FAs to $\mathrm{n}-6$ family FAs in a mother's diet may influence the stimulation or suppression of physiologically important 
processes in the body (proliferation, infections, activity of transcription factors, susceptibility to mutagenesis, apoptosis etc.) [74, 87]. It is considered that this ratio should be 1:5. In contemporary diets it is $1: 20$. The increase in the percentage of $n-6$ is caused principally by worldwide changes in dietary habits (the so-called western diet), leading to a decrease in the consumption of DHA and an increase in the proportion of AA in the diet $[87,88]$. Amongst breastfeeding Korean women, for example, DHAs are currently $0.67 \%$ of the total FAs, while twenty years ago the figure was $0.96 \%[75,89]$.

From the perspective of the physical needs of the child, the second important group of FAs present in the milk are MCFAs, mainly 10:0, 12:0 and 14:0. These FAs stabilise the bacterial flora in the child's digestive tract [90, 91], and affect the acylation and mirystosylation of protein $[92,93]$. They are also subject to quick oxydation and do not accumulate in fat tissue $[94,95]$, and, moreover, they strengthen the conversion of EPA into DHA [92, 96, 97] and fulfil a wide range of other important functions [98]. Depending on the type of milk (colostrum, transitional milk, mature milk) they make up between $4 \%$ and $27 \%$ of the total FAs in the milk [15, 99-103]. Most MCFAs are synthesised by the mammary gland from carbohydrates [104-106]. A diet rich in carbohydrates increases the concentration of MCFAs in the milk. This is due to the increased availability of carbon skeletons derived from carbohydrates, which are necessary for the synthesis of MCFAs. The amount of C8:0C14:0 in the milk is also significantly higher when the mother consumes a low-fat diet [107]. Biosynthesis of MCFAs in the mammary gland, especially C10:0 and C12:0, increases in women who gave birth before their due date and in women who gave birth to a small for gestational age (SGA) child at the due date [16]. It is not clear why this occurs. It has not been ruled out that this may be a type of placental 'programming' of the woman's body to provide milk suited to the child's needs. MCFAs appear to be a particularly good energy substrate due to the ease with which they pass through the mitochondrial membrane.

\section{Metabolism and the role of human milk FAs}

Long chain saturated FAs and LCPUFAs are sourced mainly in the mother's diet and from tissue deposits, where they are synthesised from the necessary precursors such as LA and ALA [108]. Although there is evidence for the presence of the appropriate desaturase and elongase in the mammary gland, which are enzymes responsible for the formation of $\mathrm{n}-3$ and $\mathrm{n}-6$ derived from the necessary precursors, the ability of the mammary gland to biosynthesise FAs from the n-3 and n-6 families has not as yet been confirmed $[20,109]$. MCFAs are synthesised in the mammary gland, from where they are secreted into the milk as TAGs. Complex TAGs from these FA are preferentially hydrolysed by the child's tongue and stomach lipase. During this process, free MCFAs are released, which are then quickly absorbed in the child's stomach and become one of the energy sources for this organ [110]. The unhydrolysed TAGs move into the small intestine, where they undergo further degradation under the action of pancreatic lipase. The next portion of MCFAs, released as a result of hydrolysis, are absorbed in unesterified form directly from the intestine into the circulatory system. A small proportion of these can be transported to the liver in the traditional manner, as chylomicrons. From the liver, the MCFAs are distributed around the child's whole body in the form of lipoprotein. After entering the cells, these FAs become ideal energy material. In the mitochondria, they undergo $\beta$-oxidation and release large amounts of energy in the form of adenosine triphosphate (ATP). This process is more energy efficient than $\beta$-oxidation of long chain acids as during the entry of the MCFAs into the mitochondrium, the carnitine transporter and the accompanying burning of ATP molecules are not required and this is valuable for the newborn child. Newborn babies' requirement of MCFAs, which like carbohydrates are a quickly available source of energy [111], varies depending, first and foremost, on the state of health of the newborn child. Studies have shown that the amount of MCFAs is higher both in colostrum, transitional milk and mature milk in mothers who either gave birth prematurely, gave birth to children with intrauterine growth restriction (IUGR) characteristics, or gave birth to SGA babies [30]. It has also been shown that the percentage of MCFAs in the milk is higher when the degree of immaturity of the newborn child is greater and/or the child's weight, in relation to gestational age, is lower $[30,112]$. The question remains, however, as to what the cause of the abovementioned changes in the composition of the FAs in milk is, and, in particular, the increase in the content of their medium chain forms. Some authors point to the metabolic immaturity of mammary glands in mothers of the groups of newborn babies mentioned above. According to this theory, the shortened gestational period and the impaired activity of the placenta influencing foetal hypotrophy, are factors that slow the mammary glands down in reaching full metabolic efficiency in terms of biosynthesis and secretion of milk. More probable would seem to be the theory of the existence of a mechanism regulating or adjusting the composition of the mother's milk to the current needs of the child [12,113-115]. This is probably a type of genetically programmed adaptation of the woman's body to produce and secrete milk of a composition appropriate to the age and state of health of the child $[11,114,116]$. It is possible that 
this mechanism is gradually programmed during pregnancy by the hormonal activity of the placenta, which controls the transfer of FAs from the maternal to the foetal blood circulation $[114,115]$. It is probable that at birth, or just before, the mammary gland metabolic profile in mothers of premature babies or children born with hypotrophy characteristics are programmed for the first weeks of lactation. There are more rapidly assimilable MCFAs present in the milk, and these optimise the process of energy production in these babies in the form of ATP, thus ensuring the correct functioning of basic biochemical processes in the not yet fully metabolically developed child's organism.

The next important group is LCPUFAs. These FAs are probably not synthesised by the mammary glands, even though the glands have some desaturases and elongases responsible for the lengthening and desaturation of FAs. LCPUFAs come mainly from current intake, in other words they are released from the TAGs in the intestines as chylomicrons that are transported to the liver, from which they are subsequently transported to the mammary glands as very-low-density lipoproteins (VLDLs). The second source of these is systemic biosynthesis from the necessary 18-carbon precursors, which takes place principally in the liver. The third source is fat tissue from where LCPUFAs can be released and transported to the mammary glands as nonesterified FAs in combination with albumin [20, 101, 117]. During lactation, the mammary glands release LCPUFAs from circulating lipoprotein fractions with the participation of the lipoprotein lipase within the glands. Meanwhile, the activity of lipoprotein lipase in the tissue also changes. In fat tissue, this activity decreases significantly and, thanks to this, the uptake of FAs by adipocytes is reduced. A different phenomenon is observed in the mammary glands, in which the activity of lipase increases, enabling an increased uptake of LCPUFAs and their secretion into the milk [20]. Among the almost 170 FAs found in milk, there are a few, which bear the most responsibility for a child's correct development, subject to their correct metabolism in the mother's body and correct supply in the milk. These acids include n-6 and n-3 family precursors, respectively LA, ALA and their derivatives, AA (n-6), EPA (n-3) and DHA (n-3) [120]. During pregnancy, there is already an intense accumulation of these acids in the foetal tissue, transported to the foetal circulation using specific LCPUFA transport systems [8]. As a result of these processes, the amount of some LCPUFAs such as DHA and AA in the foetal tissues is 20 or 30 times greater than in the mother's tissues [11, 12]. Just after birth, as a result of intense metabolism and an increase in the child's weight, these reserves start to quickly diminish. The only source remains the mother's milk. Irrespective of the milk secretion stage (colostrum, transitional milk, mature milk), the proportion of long chain acids and their polyunsaturated forms is relatively constant.
Even prematurity and low birth weight, irrespective of their cause (SGA, IUGR), have a relatively limited effect on the percentage of these acids in the milk. Such conclusions can be drawn on the basis of analysis of many authors' research results [29, 30, 32, 116]. However, there are groups of FAs whose amount in the mother's milk undergoes significant changes during pathology of pregnancy or in the case of illness or deficiencies in breastfeeding women. These include LCPUFAs, MCFAs and MUFAs, whose main representative is gadoleic acid (C20:1) [16].

\section{Microbiota and fatty acids of human milk}

The neonatal period represents a critical time in mammalian life with respect to the nutritional programming of gut microbiome and the immunity required to respond to infectious and other diseases, like intestinal diseases. These processes can broadly be called microbial programming of the infant immune system. To a large extent they are controlled by FAs but understanding the interrelationship between FAs and the functioning of the system is extremely difficult due to the variety of FAs found in breast milk. One of the most important groups of FAs are MCFAs. An increase in their concentration was observed in the milk of the mothers of premature babies and in SGA and IUGR babies [16, 116]. These FAs influence the activity of the child's immature immune system - mainly in terms of bacteriostatic and bactericidal activity. The particular structure of MCFAs enables them to pass relatively easily into the cell in an undissociated form, and to then undergo dissociation. This dissociation disturbs the delicate $\mathrm{pH}$ balance inside the bacteria. In an attempt to maintain a neutral $\mathrm{pH}$, the bacteria cell starts to use large amounts of ATPs in order to maintain a correct acid-alkaline balance $[90,91]$. As a result, the excessive supply of ATPs limits and finally stops other metabolic processes within the bacteria (e.g. synthesis of proteins), ultimately leading to its death $[118,119]$. The activity described above has been observed mainly in the intestines, both in people and in animals, in whom MCFAs inhibit the development of gram-positive and gram-negative bacteria [120]. It has also been observed that anti-bacterial activity is reduced together with the lengthening of the MCFA carbon chain [118]. The inhibiting properties of MCFAs are now quite well described with regard to Clostridium, Salmonella, Helicobacter and Escherichia coli [90, 91, 110] including Enteropathogenic Escherichia Coli (EPEC) which is responsible for fatal diarrhoea in infants [121]. High activity of MCFAs has also been shown to inhibit the herpes simplex virus, which, because of diarrhoea, is responsible for over 200,000 infant deaths annually worldwide [122]. 
In the case of the latter bacteria, high activity is shown principally by saturated lauric acid (C12:0 LAA) and medium length monoacylglycerols - esters in which only one hydroxyl glycerol group is substituted with a FA. LAA also increases the conversion of EPA to DHA [98], which limits the involvement of AA in the formation of pro-inflammatory molecules and promotes an increase in the biosynthesis of anti-inflammatory molecules of which DHA is a precursor. It has been proved, for example, that n-3 (DHA) reduces the production of inflammatory endotoxin-stimulated cytokines [123, 124]. In addition, it reduces the activation of NF- $\mathrm{KB}$ [125], inhibits the migration of immune cells towards chemoattractants such as leukotriene B4 and bacterial peptides [126-128] and lowers the expression of intracellular molecule 1 on stimulated monocytes [129].

\section{Conclusion}

To conclude, the composition of FAs in a woman's milk depends on many variables which shape the metabolic profile of maternal-placental-foetal changes, both in pregnancy and during lactation. These are the result of millions of years of evolution in mammals, during which milk became the sole source of natural nutrition for offspring in the first weeks of life. Milk is unique in its composition and the supramolecular structure of the compounds found within it. Of particular importance is the presence of fat globules rich in FAs and other compounds responsible for processes such as energy, growth and immunity. The composition of milk FAs is not constant. It depends on the type of milk, the secretion stage, the diet of the breastfeeding mother and the pregnancy. Differences in the amounts of various FAs in the milk indicate that a woman's body is probably adapted evolutionarily and genetically to the biosynthesis of milk with a composition adjusted to the needs and state of health of the child.

\section{References}

1. Garcia C, Innis S. Structure of the human milk fat globule. Lipid Technol. 2013;26:223-228. https://doi.org/10.1002/ lite.201390009.

2. Favre A, Szylit O, Popot F, Catala I, Rondeau C, Maurage C, et al. Diet, length of gestation, and fecal short chain fatty acids in healthy premature neonates. J Parent Enteral Nutr. 2002;26:51-56.

3. Tijerina-sáenz A, Innis SM, Kitts DD. Antioxidant capacity of human milk and its association with vitamins $A$ and $E$ fatty acid composition. Acta Paediatr. 2009;98:1793-1798.

4. Tully DB, Jones F, Tully MR. Donor milk: what's in it and what's not. J Hum Lact. 2001;17:152-155.

5. Alvino G, Cozzi V, Radaelli T, Ortega H, Herrera E, Cetin I. Maternal and fetal fatty acid profile in normal and intrauterine growth restriction pregnancies with and without preeclampsia. Pediatr Res. 2008;64:615-620.

6. Milligan LA, Bazinet RP. Evolutionary modifications of human milk composition: evidence from long chain polyunsaturated fatty acid composition of anthropoid milks. J Hum Evol. 2008;55:1086-1095.

7. Singh M. Essential fatty acids, DHA and human brain. Indian J Pediatr. 2005;72:239-242.

8. Uauy R, Mena P, Wegher B, Nieto S, Salem N Jr. Long chain polyunsaturated fatty acid formation in neonates: effect of gestational age and intrauterine growth. Pediatr Res. 2000; 47:127-135.

9. Walczewska A, Steôpień T, Bewicz-Binkowska D, Zgórzyńska E. Rola kwasu dokozaheksaenowego w czynności komórek nerwowych. Post Hig Med Dosw. 2011;65:314-327.

10. Auestad N, Scott DT, Janowsky JS, Jacobsen C, Carroll RE, Montalto MB, et al. Visual, cognitive, and language assessments at 39 months: a follow-up study of children fed formulas containing long-chain polyunsaturated fatty acids to year of age. Pediatrics. 2003;112:177-183.

11. Haggarty P. Effect of placental function on fatty acid requirements during pregnancy. Eur J Clin Nutr. 2004; 58:1559-1570.

12. Haggarty P. Placental regulation of fatty acids delivery and its effect on fetal growth - a review. Placenta. 2002;16:28-38.

13. Jensen CL, Voigt RG, Prager TC, Zou YL, Fraley JK, Rozelle $\mathrm{JC}$, et al. Effects of maternal docosahexaenoic acid intake on visual function and development in breast term infants. Am J Clin Nutr. 2005:82:125-132.

14. Ribeiro M, Balcao V, Guimaraes H, Rocha G, Moutinho C, Matos C, et al. Fatty acid profile of human milk of Portuguese lactating women: prospective study from the 1 st to the 16th week of lactation. Ann Nutr Metab. 2008;53:50-56.

15. Koletzko B, Thiel I, Abiodun PO. The fatty acid composition of human milk in Europe and Africa. J Pediatr. 1992;120:62-70.

16. Bobiński R, Mikulska M, Mojska H, Simon M. Comparison of the fatty acid composition of transitional and mature milk of mothers who delivered healthy full-term babies, preterm babies, and full-term small for gestational age infants. Eur $\mathrm{J}$ Clin Nutr. 2013;67:966-971.

17. Xiang M, Harbige LS, Zetterström R. Long-chain polyunsaturated fatty acids in Chinese and Swedish mothers: diet, breast milk and infant growth. Acta Paediatr. 2005;94:1543-9.

18. Grote V, Verduci E, Scaglioni S, Vecchi F, Contarini G, Giovannini M, et al. European Childhood Obesity Project. Breast milk composition and infant nutrient intakes during the first 12 months of life. Eur J Clin Nutr. 2016;70:250-6.

19. Innis SM. Dietary triacylglycerol structure and its role in infant nutrition. Adv Nutr. 2011;2:275-283.

20. Koletzko B, Rodriguez-Palmero M, Demmelmair H, Fidler N, Jensen R, Sauerwald T. Physiological aspects of human milk lipids. Early Hum Dev. 2001;65:3-18.

21. Uauy R, Dangour AD. Nutrition in brain development and aging: role of essential fatty acids. Nutr Rev. 2006;64:24-33.

22. Cilla A, Diego Quintaes K, Barberá R, Alegría A. Phospholipids in human milk and infant formulas: benefits and needs for correct infant nutrition. Crit Rev Food Sci Nutr. 2016;56:1880-92.

23. Claumarchirant L, Cilla A, Matencio E, Sanchez-Siles LM, Castro-Gomez P, Fontecha J, et al. Addition of milk fat globule membrane as an ingredient of infant formulas for resembling the polar lipids of human milk. Int Dairy J. 2016;61:228-238.

24. Thakkar SK, Giuffrida F, Cristina CH, De Castro CA, Mukherjee R, Tran LA, et al. Dynamics of human milk nutrient 
composition of women from Singapore with a special focus on lipids. Am J Hum Biol. 2013;25:770-9.

25. Berger A, Fleith M, Crozier G. Nutritional implications of replacing bovine milk fat with vegetable oil in infant formulas. J Pediatr Gastroenterol Nutr. 2000;30:115-30.

26. Zavaleta N, Kvistgaard AS, Graverholt G, Respicio G, Guija H, Valencia $\mathrm{N}$, et al. Efficacy of an MFGM-enriched complementary food in diarrhea, anemia, and micronutrient status in infants. J Pediatr Gastroenterol Nutr. 2011;53:561-8.

27. Timby N, Domellöf E, Hernell O, Lönnerdal B, Domellöf M. Neurodevelopment, nutrition, and growth until 12 mo of age in infants fed a low-energy, low-protein formula supplemented with bovine milk fat globule membranes: a randomized controlled trial. Am J Clin Nutr. 2014;99:860-8.

28. Demmelmair H, Koletzko B. Lipids in human milk. Best Pract Res Clin Endocrinol Metab. 2018;32:57-68.

29. Tinoco SM, Sichieri R, Setta CL, Moura AS, Taraves Do Carmo MG. Trans fatty acids from milk of Brazilian mothers of premature infants. J Paed Child Health. 2008;44:50-56.

30. Moltó-Puigmartí C, Castellote Al, Carbonell-Estrany X, López-Sabater MC. Differences in fat content and fatty acid proportions among colostrum, transitional, and mature milk from women delivering very preterm, preterm, and term infants. Clin Nutr. 2011;30:116-123.

31. Al-Tamer YY, Mahmood AA. The influence of Iraqi mothers' socioeconomic status on their milk-lipid content. Eur J Clin Nutr. 2006;60:1400-1405.

32. Bokor S, Koletzko B, Decsi T. Systematic review of fatty acid composition of human milk from mothers of preterm compared to full-term infants. Ann Nutr Metab. 2007;51:550-556.

33. Smit EN, Martini IA, Mulder H, Boersma ER, Muskiet FAJ. Estimated biological variation of the mature human milk fatty acid composition. Prostagl Leukotr Essent Fatty Acids. 2002;66:549-555.

34. Wan ZX, Wang XL, Xu L, Geng Q, Zhang Y. Lipid content and fatty acids composition of mature human milk in rural North China. Br J Nutr. 2010;103:913-916.

35. Kent JC, Mitoulas LR, Cregan MD, Ramsay DT, Doherty DA, Hartmann PE. Volume and frequency of breastfeedings and fat content of breast milk throughout the day. Pediatrics. 2006;117:387-95.

36. Marangoni F, Agostoni C, Lammardo AM, Giovannini M, Galli C, Riva E. Polyunsaturated fatty acid concentrations in human hindmilk are stable throughout 12 -months of lactation and provide a sustained intake to the infant during exclusive breastfeeding: an Italian study. $\mathrm{Br} J$ Nutr. 2000;84:103-109.

37. Atwood CS, Hartmann PE. Collection of fore and hind milk from the sow and the changes in milk composition during suckling. J Dairy Res. 1992;59:287-298.

38. Innis SM. Impact of maternal diet on human milk composition and neurological development of infants. Am J Clin Nutr. 2014;99:734-41.

39. Del Prado M, Villalpando S, Elizondo A, Rodríguez M, Demmelmair $\mathrm{H}$, Koletzko B. Contribution of dietary and newly formed arachidonic acid to human milk lipids in women eating a low-fat diet. Am J Clin Nutr. 2001;74:242247.

40. Garg M, Bassilian S, Bell C, Lee S, Lee WNP. Hepatic de novo lipogenesis in stable low-birth-weight infants during exclusive breast milk feedings and during parenteral nutrition. $J$ Parent Enteral Nutr. 2005;26:81-86.

41. Opinion on establishing Food-Based Dietary Guidelines EFSA Panel on Dietetic Products, Nutrition, and Allergies (NDA) European Food Safety Authority (EFSA), Parma, Italy. Scien- tific Opinion on establishing Food-Based Dietary Guidelines. EFSA Journal. 2010;8(3):1462.

42. Food and Agriculture Organization of the United Nations. Fat and fatty acid during pregnancy and lactation. In Fats and fatty acids in human nutrition Report of an expert consultation (FAO Food and Nutrition Paper, no. 91, pp 7786). Geneva: World Health Organization. 2010.

43. Maas C, Franz AR, Shunova A, Mathes M, Bleeker C, Poets $\mathrm{CF}$, et al. Choline and polyunsaturated fatty acids in preterm infants' maternal milk. Eur J Nutr. 2017;56:1733-1742.

44. Crawford M. Placental delivery of arachidonic and docosahexaenoic acids: implications for the lipid nutrition of preterm infants. Am J Clin Nutr. 2000;71:275S-84S.

45. Wikland KA, Luo ZC, Niklasson A, Karlberg J. Swedish population-based longitudinal reference values from birth to 18 years of age for height, weight and head circumference. Acta Paediatr. 2002;91:739-54.

46. Peng Y, Zhou T, Wang Q, Liu P, Zhang T, Zetterström R, et al. Fatty acid composition of diet, cord blood and breast milk in Chinese mothers with different dietary habits. Prostaglandins Leukot Essent Fatty Acids. 2009;81:325-30.

47. Voigt M, Rochow N, Straube S, Briese V, Olbertz D, Jorch G. Birth weight percentile charts based on daily measurements for very preterm male and female infants at the age of 154223 days. J Perinat Med. 2010;38:289-95.

48. Calder PC, Dangour AD, Diekman C, Eilander A, Koletzko B, Meijer GW, et al. Essential fats for future health. 2010.

49. Dobbing J, Sands J. Quantitative growth and development of human brain. Arch Dis Child. 1973;48:757-767.

50. Tau GZ, Peterson BS. Normal development of brain circuits. Neuropsychopharmacology. 2010;35:147-168.

51. Knickmeyer R, Gouttard S, Kang C, Evans D, Wilber K, Smith $J$, et al. A structural MRI study of human brain development from birth to 2 years. J Neurosci. 2008;28:12176-82.

52. Levitt P. Structural and functional maturation of the developing primate brain. J Pediatr. 2003;143:S35-45.

53. Innis SM. Dietary $(n-3)$ fatty acids and brain development. $J$ Nutr. 2007;137:855-9.

54. Pitcher J, Riley A, Doeltgen S, Kurylowicz L, Rothwell J, McAllister S, Smith AE, Clow A, Kennaway DJ, Ridding MC, et al. Physiological evidence consistent with reduced neuroplasticity in human adolescents born preterm. J Neurosci. 2012;32:16410-6.

55. Parchem K, Bartoszek A. Phospholipids and products of their hydrolysis as dietary preventive factors for civilization diseases. Post Hig Med Dosw. 2016;70:1343-1361.

56. Kingsley M. Effects of phosphatidylserine supplementation on exercising humans. Sports Med. 2006;36:657-669.

57. Vance JE, Steenbergen R. Metabolism and functions of phosphatidylserine. Prog Lipid Res. 2005;44:207-234.

58. Richter Y, Herzog Y, Lifshitz Y, Hayun R, Zchut S. The effect of soybean-derived phosphatidylserine on cognitive performance in elderly with subjective memory complaints: a pilot study. Clin Interv Aging. 2013;8:557-563.

59. Hellhammer J, Vogt D, Franz N, Freitas U, Rutenberg D. A soybased phosphatidylserine/phosphatidic acid complex (PAS) normalizes the stress reactivity of hypothalamuspituitary-adrenal-axis in chronically stressed male subjects: a randomized, placebo-controlled study. Lipids Health Dis. 2014;13:121.

60. Uauy R, Mena P, Rojas C. Essential fatty acids in early life: structural and functional role. Proc Nutr Soc. 2000;59:3-15.

61. Makrides M, Simmer K, Neumann M, Gibson R. Changes in the polyunsaturated fatty acids of breast milk from mothers of full-term infants over 30 wk of lactation. Am J Clin Nutr. 1995:61:1231-1233. 
62. Demmelmair H, Baumheuer M, Koletzko B, Dokoupil K, Kratl G. Metabolism of U13C-labeled linoleic acid in lactating women. J Lipid Res. 1998;39:1389-1396.

63. Villalpando S, Del Prado M, Lance A, Alfonso E, Rodríguez M, Demmelmair $\mathrm{H}$, et al. [13C] linoleic acid oxidation and transfer into milk in stunted lactating women with contrasting body mass indexes. Am J Clin Nutr. 2001;74:827-832.

64. Demmelmair H, Kuhn A, Dokoupil K, Hegele V, Sauerwald T, Koletzko B. Human lactation: oxidation and maternal transfer of dietary (13) C-labelled $\alpha$-linolenic acid into human milk. Isotopes Environ Health Stud. 2016;52:270-280.

65. Francois C, Connor S, Bolewicz L, Connor W. Supplementing lactating women with flaxseed oil does not increase docosahexaenoic acid in their milk. Am J Clin Nutr. 2003;77:226233.

66. Mazurier E, Rigourd V, Perez P, Buffin R, Couedelo L, Vaysse C, et al. Effects of maternal supplementation with omega-3 precursors on human milk composition. J Hum Lact. 2017;33:319-328.

67. Valenzuela R, Bascuñán K, Chamorro R, Barrera C, Sandoval J, Puigrredon C, et al. Modification of docosahexaenoic acid composition of milk from nursing women who received alpha linolenic acid from chia oil during gestation and nursing. Nutrients. 2015;7:6405-6424.

68. Koletzko B, Boey CC, Campoy C, Carlson SE, Chang N, Guillermo-Tuazon MA, et al. Current information and Asian perspectives on long-chain polyunsaturated fatty acids in pregnancy, lactation, and infancy: systematic review and practice recommendations from an early nutrition academy workshop. Ann Nutr Metab. 2014;65:49-80.

69. Ross B, Seguin J, Sieswerda LE. Omega-3 fatty acids as treatments for mental illness: which disorder and which fatty acid? Lipids Health Dis 2007;6:21.

70. Koletzko B, Lien E, Agostoni C, Böhles H, Campoy C, Cetin I, et al. The roles of long-chain polyunsaturated fatty acids in pregnancy, lactation and infancy: review of current knowledge and consensus recommendations World Association of Perinatal Medicine Dietary Guidelines Working Group. J Perinatal Med. 2008;36:5-14.

71. Lafond J, Moukdar F, Rioux A, Ech-Chadli H, Brissette L, Robidoux J, et al. Implication of ATP and sodium in arachidonic acid incorporation by placental syncytiotrophoblast brush border and basal plasma membranes in the human. placenta. 2000;21:661-669.

72. Llanos A, Li Y, Mena P, Salem N. Infants with intra uterine growth restriction have impaired formation of docosahexaenoic acid in early neonatal life: a stable isotope study. Pediatric Res. 2005;58:735-740.

73. Antonakou A, Skenderi K, Chiou A, Anastasiou C, Bakoula C, Matalas A. Breast milk fat concentration and fatty acid pattern during the first six months in exclusively breastfeeding Greek women. Eur J Nutr. 2013;52:963-973.

74. Liu M, Li H, Yu L, Xu G, Ge H, Wang L, et al. A correlation study of DHA dietary intake and plasma, erythrocyte and breast milk DHA concentrations in lactating women from coastland, lakeland, and inland areas of China. Nutrients. 2016;8:312-323.

75. Golfetto I, McGready R, Ghebremeskel K, Min Y, Dubowitz L, Nosten F, et al. Fatty acid composition of milk of refugee Karen and urban Korean mothers. Is the level of DHA in breast milk of Western women compromised by high intake of saturated fat and linoleic acid? Nutr Health 2007;18:319-332.

76. Brenna J, Varamini B, Jensen R, Diersen-Schade D, Boettcher J, Arterburn L. Docosahexaenoic and arachidonic acid concentrations in human breast milk worldwide. Am J Clin Nutr. 2007;85:1457-1464.
77. Fidler N, Sauerwald T, Pohl A, Demmelmair H, Koletzko B. Docosahexaenoic acid transfer into human milk after dietary supplementation: a randomized clinical trial. J Lipid Res. 2000;41:1376-83.

78. Sherry C, Oliver J, Marriage B. Docosahexaenoic acid supplementation in lactating women increases breast milk and plasma docosahexaenoic acid concentrations and alters infant omega 6:3 fatty acid ratio. Prostaglandins Leukot Essent Fatty Acids. 2015;95:63-69.

79. Helland I, Saarem K, Saugstad OD, Drevon CA. Fatty acid composition in maternal milk and plasma during supplementation with cod liver oil. Eur J Clin Nutr. 1998;52:839845.

80. Makrides M, Neumann M, Gibson R. Effect of maternal docosahexaenoic acid (DHA) supplementation on breast milk composition. Eur J Clin Nutr. 1996;50:352-357.

81. Vannice G, Rasmussen $H$. Position of the academy of nutrition and dietetics: dietary fatty acids for healthy adults. J Acad Nutr Diet. 2014;114:136-153.

82. Yakes E, Arsenault J, Islam M, Hossain M. Intakes and breast-milk concentrations of essential fatty acids are low among Bangladeshi women with 24-48-month-old children. Br J Nutr. 2011;105:1660-1670.

83. Nyuar K, Min Y, Ghebremeskel K, Khalil AK, Elbashir M, Cawford M. Milk of northern Sudanese mothers whose traditional diet is high in carbohydrate contains low docosahexaenoic acid. Acta Paediatr. 2010;99:1824-7.

84. Glew R, Wold R, Corl B, Calvin C, VanderJagt D. Low docosahexaenoic acid in the diet and milk of American Indian women in New Mexico. J Am Diet. Assoc. 2011;111:744-748.

85. Bobiński R, Mikulska M, Mojska H, Ulman-Wtodarz I. The dietary composition of women who delivered healthy fullterm infants, preterm infants, and full-term infants who were small for gestational age. Biol Res Nurs. 2015;17:495502.

86. Jia X, Pakseresht M, Wattar N, Wildgrube J, Sontag S, Andrews $\mathrm{M}$, et al. Women who take $\mathrm{n}-3$ long-chain polyunsaturated fatty acid supplements during pregnancy and lactation meet the recommended intake. Appl Physiol Nutr Metab. 2015;40:474-481.

87. Larsson S, Kumlin M, Ingelman-Sundberg M, Wolk A. Dietary long-chain n-3 fatty acids for the prevention of cancer: a review of potential mechanisms. Am $J$ Clin Nutr. 2004;79:935-945.

88. Küllenberg D, Taylor L, Schneider M, Massing U. Health effects of dietary phospholipids. Lipids Health Dis. 2012;11:3.

89. Hyesook K, Sujeong K, Byung-Moon J, Hyunju Y, Ji A, Namsoo C. Breast milk fatty acid composition and fatty acid intake of lactating mothers in South Korea. $\mathrm{Br} J$ Nutr. 2017;117:556-561.

90. Marounek M, Skrivanova E, Rada V. Susceptibility of Escherichia coli to $\mathrm{C} 2-\mathrm{C} 18$ fatty acids. Folia Microbiol. 2003:48:731-735.

91. Skrivanowa E, Marounek M, Benda V, Brezina P. Susceptibility of Escherichia coli, Salmonella sp. and Clostridium perfringens to organic acids and monolaurin. Vet Med. 2006;51:81-88.

92. Jan S, Guillou H, D’Andrea S, Daval S, Bouriel M, Rioux V, et al. Myristic acid increases $\Delta 6$-desaturase activity in cultured rat hepatocytes. Reprod Nutr Dev. 2004;44:131-140.

93. Rioux V, Catheline D, Bouriel Legrand P. Dietary myristic acid at physiologically relevant levels increases the tissue content of C20:5n-3 and C20:3n-6 in the rat. Repr Nutr Dev. 2005;45:599-612. 
94. Geliebter A, Torbay N, Bracco E, Hashim S, Van Itallie $\mathrm{T}$. Overfeeding with medium chain triglyceride diet results in diminished deposition of fat. Am J Clin Nutr. 1983;37:1-4.

95. Tachibana S, Sato K, Cho Y, Chiba T, Schneider W, Akiba Y. Octanoate reduces very low-density lipoprotein secretion by decreasing the synthesis of apolipoprotein B in primary cultures of chicken hepatycytes. Biochim Biophys Acta. 2005;1737:36-43.

96. Legrand P, Catheline D, Rioux V, Durand G. Lauric acid is desaturated to C12:1 n-3 by rat liver homogenate and hapatocytes. Lipids. 2002;37:569-572.

97. Legrand P, Rioux V. The complex and important cellular and metabolic functions of saturated fatty acids. Lipids. 2010;45:941-946.

98. Bobiński R, Mikulska M. The ins and outs of maternal-fetal fatty acid metabolism. Acta Biochim Pol. 2015;62:499-507.

99. Jensen R. ed. Handbook of milk composition. San Diego, CA: Academic Press 1995.

100. Innis S. Human milk and formula fatty acids. J Pediatr. 1992;120:S56-61.

101. Brenna J, Varamini B, Jensen R, Diersen-Schade D, Boettcher J, Arterburn L. Docosahexaenoic and arachidonic acid concentrations in human breast milk worldwide. Am J Clin Nutr. 2007:85:1457-64.

102. Innis S. Polyunsaturated fatty acids in human milk: an essential role in infant development. Adv Exp Med Biol. 2004;554:27-43.

103. Innis S. Maternal nutrition, genetics and human milk lipids. Curr Nutr Rep. 2013;2:151-8.

104. Annison E, Linzell J, Fazakerley S, Nichols B. The oxidation and utilization of palmitate, stearate, oleate and acetate by the mammary gland of the fed goat in relation to their overall metabolism, and the role of plasma phospholipids and neutral lipids in milk-fat synthesis. Biochem J. 1967;102:637-647.

105. Carey E, Dils R. The pattern of fatty acid synthesis in lactating rabbit mammary gland studied in vivo. Biochem $\mathrm{J}$. 1972;126:1005-1007.

106. Cowie A, Duncombe W, Folley S, French T, Glascock R. Synthesis of milk fat from acetic acid $(\mathrm{CH} 314 \mathrm{COOH})$ by the perfused isolated bovine udder. Biochem J. 1951;49:610615.

107. Nasser R, Stephen A, Goh Y, Clandin M. The effect of a controlled manipulation of maternal dietary fat intake on medium and long chain fatty acids in human breast milk in Saskatoon, Canada. Int Breastfeeding J. 2010;5:1-6.

108. Pilar L, Manuela J, De la Fuente M. Fatty acid and conjugated linoleic acid isomer profiles in human milk fat. Eur J Lipid Sci Technol. 2007;109:1160-1166.

109. Merino D, Ma D, Mutch D. Genetic variation in lipid desaturases and its impact on the development of human disease. Lipids Health Dis. 2010;9:63-71.

110. Szewczyk A, Hanczakowska E. Właściwości i zastosowanie średniołańcuchowych kwasów tłuszczowych (MCFA) i ich monoacylgliceroli (MCM). Wiad Zootech. 2010;1:21-26.

111. Fushiki T, Mat sumoto K. Swimming endurance capacity of mice is increased by consumption of medium - chain triglycerides. J Nutr. 1995;125:531.

112. Bier J, Oliver T, Ferguson A, Vohr B. Human milk improves cognitive and motor development of premature infants during infancy. J Hum Lact. 2002;18:361-367.

113. Bauer J, Gerss J. Longitudinal analysis of macronutrients and minerals in human milk produced by mothers of preterm infants. Clin Nutr. 2011;30:215-220.
114. Herrera E. Implications of dietary fatty acids during pregnancy on placental, fetal and postnatal development - a review. Placenta. 2002;16:9-19.

115. Pardi G, Marconi A, Cetin I. Placental-fetal interrelationship in IUGR fetuses - a review. Placenta. 2002;23:136-141.

116. Smithers L, Markrides M, Gibson R. Human milk fatty acids from lactating mothers of preterm infants: A study revealing wide intra- and inter-individual variation. Prostagl Leukotr Essent Fatty Acids. 2010;83:9-13.

117. Leaf D, Connor W, Barstad L, Sexton G. Incorporation of dietary $n-3$ fatty acids into the fatty acids of human adipose tissue and plasma lipid classes. Am J Clin Nutr. 1995;62:6873.

118. Ricke S. Perspectives on the use of organic acids and short chain fatty acids as antimicrobials. Polutry Sci. 2003;82: 632-639.

119. Nakai S, Siebert K. Validation of bacterial growth inhibition models based on molecular properties of organic acids. $J$ Food Microbiol. 2002;2678:1-7.

120. Weseler A, Dirix C, Bruins M, Hornstra G. Dietary arachidonic acid dose-dependently increases the arachidonic acid concentration in human milk. J Nutr. 2008;138:2190-2197.

121. Quin C, Gibson D. Dietary fatty acids and host-microbial crosstalk in neonatal enteric infection. Nutrients. 2019;11:2064. https://doi.org/10.3390/nu11092064.

122. Thormar $H$, Isaacs $C$, Brown $H$, Barshatzky M, Pessolano $T$. Inactivation of enveloped viruses and killing of cells by fatty acids and monoglycerides. Antimicrob. Agents Chemother. 1987;31:27-31. https://doi.org/10.1128/AAC.31.1.27

123. Caughey G, Mantzioris E, Gibson R, Cleland L, James M. The effect on human tumor necrosis factor alpha and interleukin 1 beta production of diets enriched in $n-3$ fatty acids from vegetable oil or fish oil. Am. J. Clin. Nutr. 1996;63:116-122. https://doi.org/10.1093/ajcn/63.1.116.

124. Endres S, Ghorbani R, Kelley V, Georgilis K, Lonnemann G, van der Meer J, Cannon J, Rogers T, Klempner M, Weber P, et al. The effect of dietary supplementation with $n-3$ polyunsaturated fatty acids on the synthesis of interleukin-1 and tumor necrosis factor by mononuclear cells. N. Engl. J. Med. 1989;320:265-271. https://doi.org/ 10.1056/NEJM198902023200501.

125. Zhao Y, Joshi-Barve S, Barve S, Chen L. Eicosapentaenoic acid prevents LPS-induced TNF-alpha expression by preventing NF-kappaB activation. J. Am. Coll. Nutr. 2004;23:7178. https://doi.org/10.1080/07315724.2004.10719345.

126. Schmidt E, Pedersen J, Ekelund S, Grunnet N, Jersild C, Dyerberg J. Cod liver oil inhibits neutrophil and monocyte chemotaxis in healthy males. Atherosclerosis. 1989;77:5357. https://doi.org/10.1016/0021-9150(89)90009-9.

127. Schmidt E, Varming K, Pedersen J, Lervang H, Grunnet N, Jersild C, Dyerberg J. Long-term supplementation with $n-3$ fatty acids, II: Effect on neutrophil and monocyte chemotaxis. Scand. J. Clin. Lab. Invest. 1992;52:229-236. https:// doi.org/10.3109/00365519209088790.

128. Sperling R, Benincaso A, Knoell C, Larkin J, Austen K, Robinson D. Dietary omega-3 polyunsaturated fatty acids inhibit phosphoinositide formation and chemotaxis in neutrophils. J. Clin. Investig. 1993;91:651-660. https://doi.org/ 10.1172/JCl116245.

129. Hughes D, Pinder A, Piper Z, Johnson I, Lund E. Fish oil supplementation inhibits the expression of major histocompatibility complex class $\|$ molecules and adhesion molecules on human monocytes. Am. J. Clin. Nutr. 1996;63: 267-272. https://doi.org/10.1093/ajcn/63.2.267. 


\section{History}

Received October 21, 2019

Accepted March 14, 2020

Published online April 21, 2020

\section{Acknowledgement}

The author wishes to acknowledge Mr. Robert Paprotny for his help in preparing figures 1 and 3 .

\section{Conflict of interest}

The authors declare that there are no conflicts of interest.

\section{Authors' contributions}

The whole manuscript was prepared by the authors

\section{ORCID}

Rafał Bobiński

(D) https://orcid.org/0000-0002-3649-5653

\section{Rafat Bobiński}

University of Bielsko-Biala

Faculty of Health Sciences

Department of Biochemistry and Molecular Biology

Willowa street 2

43-309 Bielsko-Biala

Poland

wnoz@ath.bielsko.pl 